\title{
Volatility Modelling of Global Financial Crises Effects on the Nigerian Banks
}

\author{
Maruf A. Raheem ${ }^{1,2^{*}}$, Timothy K. Samson ${ }^{3}$ \\ ${ }^{1}$ Department of and Engineering and Mathematics, Sheffield Hallam University, Sheffield, United Kingdom \\ ${ }^{2}$ Department of Statistics, University of Uyo, Uyo, Nigeria \\ ${ }^{3}$ Statistics Programme, College of Engineering, Agriculture and Science, Bowen University, Iwo, Osun State, Nigeria \\ Email: ${ }^{\star}$ rahemarsac@yahoo.com, kayode.samson@bowen.edu.ng
}

How to cite this paper: Raheem, M.A. and Samson, T.K. (2020) Volatility Modelling of Global Financial Crises Effects on the Nigerian Banks. Open Journal of Statistics, 10, 303-324.

https://doi.org/10.4236/ojs.2020.102021

Received: March 14, 2020

Accepted: April 19, 2020

Published: April 22, 2020

Copyright $\odot 2020$ by author(s) and Scientific Research Publishing Inc. This work is licensed under the Creative Commons Attribution International License (CC BY 4.0).

http://creativecommons.org/licenses/by/4.0/

\begin{abstract}
The most appropriate heteroskedastic models for predicting volatility of daily stocks prices of 10 major Nigerian banks are proposed. The banks are Access, United Bank for Africa (UBA), Guaranty Trust, Skye, Diamond, Fidelity, Sterling, Union, ETI and Zenith banks; and these are examined from 2004 to 2014. The models employed are Autoregressive Conditional Heteroscedastic (ARCH(1)), Generalized Autoregressive Conditional Heteroscedastic $(\operatorname{GARCH}(1,1))$, Exponential Generalized Autoregressive Conditional Heteroscedastic (EGARCH(1, 1)) and Glosten, Jagananthan and Runkle-Generalized Autoregressive Conditional Heteroscedastic (GJR-GARCH(1, 1)). The results show that all the bank returns are highly leptokurtic, significantly skewed and thus non-normal across the four periods except for Fidelity bank during financial crises; findings similar to those of other global markets. Also noticed is the strong evidence for the presence of heteroscedasticity, and that volatility persistence during crisis is higher than before the crisis across the 10 banks, with that of UBA taking the lead, about 11 times higher during the crisis. The same with persistence levels in volatility, which were relatively higher during financial crises across the ten banks compared to before the crises. Findings further indicate that Asymmetric GARCH models outperformed the symmetric GARCH models, especially during the financial crises and post the crises. Thus with these findings, one could generally conclude that Nigerian banks' returns are volatility persistent during and after the crises, and are characterized by leverage effects of negative and positive shocks during these periods.
\end{abstract}

\section{Keywords}

Global Financial Crisis, Leverage Effect, Nigerian Stock Exchange,

Volatility Clustering, Persistence 


\section{Introduction}

Modelling volatility dynamics are central to many issues such as: credit spreads derivative prices, leverage ratios, and portfolio theories in financial markets. Volatility is a measure of liquidity in the market [1] because to (risk-averse) investors, high volatility is associated with high risks in investment thereby forcing investors to move funds to less risky assets. [1] notes that the presence of apparent spikes in volatility and large movements in asset prices due to financial crises makes estimation of volatility and volatility dynamics difficult (or challenging) as against the periods of low market volatility when estimating and understanding volatility dynamics becomes relatively easy. However in recent times, series of financial crunch experienced across the global markets negatively impacted market volatility and foreign investors' chances of diversifying their investments.

The 2007-2009 global financial crisis which has its root from the sub-prime mortgage lending in the United States of America (USA) spread rapidly and systemically across developed and emerging markets in an unprecedented manner in the global financial crises history not seen since the early 1930s. Usually due to financial crisis, stock market volatility rises very high due to a heavy drop in stock prices across global markets; with the effects on the emerging markets remaining heavy and persistent [2]. Due to contagion, a strongly volatile market characterised by negative returns would naturally impact any known financial market running an open economy. According to several studies, stock market volatility rose after the global financial meltdown across various markets of both developed and emerging economies [3] [4] [5] [6]. According to [4], volatility went up at the time of financial meltdown but dropped shortly after the period of crisis. Given these findings, it is then imperative to examine how much impact the 2007-2009 global financial crisis had on the Nigerian capital market, particularly the banking industry.

Our interest on the banking sector is premised on the role banks play in any economy and that they are always at the centre of any crisis to such an extent that when hit by the crisis without prompt action the entire economy is set at risk. Moreover in the Nigerian situation, this sector has gone through a series of financial reforms in recent times, some of which were initiated due to the failure of most of the banks to meet their capital adequacies and lack of corporate governance amidst other inefficiencies in their operations. The Nigerian economy was shielded away from the first round effects of the 2007-2009 global financial crises due to strong control and monitoring by the Central Bank of Nigeria (CBN) and the federal government of the economy in general.

However, the spillover effects of the second round effects of these crises which hit the capital market leading to the market crash forced the relevant regulatory bodies to initiate another financial reform, much of which was focused on the Nigerian banks due to heavy dependence of some of these banks on the stock market and the oil \& gas industries in 2009 [7].

The question is how much these crises and various financial reforms had shaped the Nigerian banks in terms of the stock volatility in their equity returns 
over the periods of this study? It is hoped to identify what level of persistence in volatility was experienced by each of these banks and which of the ARCH/GARCH family models would best describe patterns of volatility witnessed across the various periods of the indicated scenarios.

Modelling stock volatility is indeed challenging given the stylized facts characterising financial data; among which non-linearity and time-varying behaviour of the asset variance (and covariance) have been found to have made the conventional (or linear) econometric models unfit for empirical situations (see: [8]-[13]). This necessitated the development of the heteroscedastic family of econometric models first developed by [8] and [9].

Other papers have studied similar aspects of volatility. For example, [14] and [15], examine the impact of arrival rates of trading information on the volatility; [16] investigates the impact of calendar time scale on the volatility; [17] establishes that market crashes lead to significant negative skewness in stock returns; [13], apply GARCH models to capture non-linearity in financial data; [18] examine effects of United States (US) sub-prime housing problems on the Malaysia market volatility; the same with [19], but on the US stocks through S \& P 500 index; [1] and [3] investigate the effects of the global financial crisis on both Czech Republic and Polish capital markets; and [5] apply the EGARCH model to India and Pakistan markets.

In the light of the above, this research will generate useful findings that would significantly help relevant stakeholders in the Nigeria financial market, to identify the areas of concerns so that effective policies or strategies that would reposition not only the banking industry but the entire market could be initiated.

Besides the current section which covers the introduction and some relevant literature, the rest of the study is structured in such a way that Section 2 is dedicated to presenting the data, discussing the methodologies and study design adopted in addressing the objectives of the research. Section 3 presents and discusses the results of the analyses while Section 4 has the summary and conclusion on the findings of this research.

\section{Data Presentation and Methodology}

\subsection{Data Presentation}

The data (obtained from http://www.cashcraft.com/), consist of daily closing stock prices of the ten banks making Nigerian Security Exchange (NSE)'s Banking index from August 2004 to May, 2014, covering the periods of financial crises and reforms in the industry. These banks are: Access, United Bank for Africa (UBA), Guaranty Trust, Skye, Sterling Bank, Diamond, Fidelity Bank, Union Bank Plc, Eco Bank and Zenith Bank. The periods considered in this research have however been divided into: 1) Overall Period: August, 2004 to May, 2014 and 2) Financial Crisis Period: July 2007-June, 2009.

The returns are generated from the stock prices using the formula:

$$
r_{t}=\log \left(R_{t}\right)=\log \left(P_{t}\right)-\log \left(P_{t-1}\right)=p_{t}-p_{t-1}
$$


where $R_{t}$, is the simple return at time $t$, derived as: $R_{t}=\frac{P_{t}-P_{t-1}}{P_{t-1}}, P_{t}$ is the stock closing price at time $t$ and $P_{t-1}$ closing price at time $t-1 ; r_{t}$ is called geometric or continuously compounded return; used for analysing stock data, $p_{t}$ is the log of price at time " $t$ " and $p_{t-1}$ is the log of price at time " $t-1$ " period preceding time " $t$ ".

Having generated returns from the daily closing prices of the stocks for each bank, both price and returns series are produced; subsequently, descriptive statistics of the series are obtained. Then stationarity tests are performed, followed by fitting Autoregressive Moving Average (ARMA) models. The residuals from these are examined for the presence of ARCH effect (or heteroscedasticity). Finally, an appropriate ARCH/GARCH family model is fitted to each of the series across the different epochs indicated above.

\subsection{Methodology}

Four mostly explored heteroscedasticity models in financial econometrics are discussed with some of their properties also highlighted. It could be recalled that financial data are subject to heavy tails, which is why these models are becoming popular in the field of econometrics. The Autoregressive Conditional Heteroscedastic (ARCH) family models according to [20] are adopted in modelling financial data for a number of reasons which include simplicity and ease of ability to handle clustered errors and changes in the econometricians' leverage to make predictions.

\subsection{ARCH( $(p)$ Model}

Suppose the return on a period " $t$ " is expressed as:

$$
r_{t}=\mu+\varepsilon_{t}
$$

where " $\mu$ " stands for unconditional mean return for period " $t$ ".

Thus, $\varepsilon_{t}=\left(r_{t}-\mu\right)$, the shock of an asset return, it is serially uncorrelated but dependent and its dependence can be defined by a quadratic function of its lagged values [21].

Ordinarily,

$$
\varepsilon_{t}=\sigma_{t} z_{t}
$$

where $\left\{z_{t}\right\}$, stands for sequence of independent and identically distributed (iid) random variables, with mean $\left[E\left(z_{t}\right)=0\right],[22]$ and variance $\left[V\left(z_{t}\right)=1\right]$. For $\operatorname{ARCH}(1)$, the conditional volatility is computed from

$$
\sigma_{t}^{2}=\alpha_{0}+\alpha_{1} \varepsilon_{t-1}^{2}
$$

Given that $\alpha_{0}>0$ and $0<\alpha_{1}<1$, then Equation (4) is said to be positive and stationary

The unconditional volatility for $\mathrm{ARCH}(1)$ can then be derived from Equation (4) as: 


$$
\sigma^{2}=\frac{\alpha_{0}}{1-\alpha_{1}}
$$

where $\alpha_{0}$ is the long run volatility, $\alpha_{1}$ is the coefficient of heteroscedasticity (or measure of ARCH effect).

The unconditional Kurtosis for Equation (4) is then:

$$
k_{4}=\frac{3\left(1-\alpha_{1}^{2}\right)}{1-3 \alpha_{1}^{2}}>3 \text { iff } 3 \alpha_{1}^{2}<1
$$

\section{4. $\operatorname{GARCH}(p, q)$}

The GARCH process by [9] requires joint estimation of mean and the conditional variance equations under the assumption that the associated error term, $a_{t}$, follows a normal process with zero mean and time-varying conditional variance. Again consider the mean equation:

$$
r_{t}=\mu+\varepsilon_{t}
$$

Such that $\varepsilon_{t}=\sigma_{t} z_{t}$; but for $\operatorname{GARCH}(1,1)$, the volatility is:

$$
\sigma_{t}^{2}=\alpha_{0}+\alpha_{1} \varepsilon_{t-1}^{2}+\beta_{1} \sigma_{t-1}^{2}
$$

Given that $\alpha_{0}>0, \alpha_{1}>0, \beta_{1}>0$ and $\alpha_{1}+\beta_{1}<1$; then Equation (7) is both positive and covariance stationary.

The unconditional expectation of Equation (7) is derived as:

$$
E\left[\sigma_{t}^{2}\right]=\frac{\alpha_{0}}{1-\alpha_{1}-\beta_{1}}=\sigma^{2}
$$

The unconditional Kurtosis for Equation (8) could also be derived as:

$$
k_{4}=\frac{3\left(1-\left(\alpha_{1}+\beta_{1}\right)^{2}\right)}{1-\left(3 \alpha_{1}^{2}+2 \alpha_{1} \beta_{1}+\beta_{1}^{2}\right)}>3 \text { iff } 3 \alpha_{1}^{2}+2 \alpha_{1} \beta_{1}+\beta_{1}^{2}<1
$$

$\beta_{1}$ is the coefficient of the GARCH effect, $\alpha_{1}$ is the parameter for ARCH effect while the sum $\left(\alpha_{1}+\beta_{1}\right)$ represents a measure of volatility persistence. So when $\left(\alpha_{1}+\beta_{1}\right)=1$, there is the presence of a unit root in the GARCH process, meaning shocks to volatility persist infinitely; there by resulting in a new process called the Integrated Generalized Autoregressive Conditional heteroscedastic (IGARCH) model.

\subsection{GJR GARCH}

The GJR-GARCH model is an extension of GARCH with a leverage parameter which allows for leverage effects in the returns and was developed by [23] to correct the limitation of the standard GARCH model of its inability to respond to past negative innovations differently from positive ones.

Thus for GJR-GARCH $(1,1)$, the conditional volatility is

$$
\sigma_{t}^{2}=\alpha_{0}+\alpha_{1} \varepsilon_{t-1}^{2}+\gamma_{1} \varepsilon_{t-1}^{2} I_{t-1}+\beta_{1} \sigma_{t-1}^{2}
$$

where $I_{t-1}$ (indicator parameter), is the leverage effect indicator parameter and 
could be defined as:

$$
I_{t-1}= \begin{cases}1, & \text { if } \varepsilon_{t-1}<0 \text { indicating bad news } \\ 0, & \text { if } \varepsilon_{t-1} \geq 0 \text { indicating good news }\end{cases}
$$

From the model, the impact of good news on volatility is measured by $\alpha_{i}$, whereas bad news impact on volatility is determined by $(\alpha+\gamma)$. This means negative shock has a greater impact on subsequent volatility for, $\varepsilon_{t-1}<0$. News impact is asymmetric only if $\gamma \neq 0$, but when $\gamma>0$ it indicates a leverage effect is present. To satisfy non-negativity condition coefficients, $\alpha_{0} \geq 0, \alpha_{1}>0$, $\beta_{1} \geq 0$ and $(\alpha+\gamma)>0$. The shock persistence is measured by $\alpha_{1}+\beta_{1}+\frac{\gamma}{2}$, [24] which becomes covariance and strictly stationary when it is less than one.

However, according to [25], this model will still be good even if $\gamma<0$ given that $(\alpha+\gamma) \geq 0$.

\subsection{Exponential GARCH}

Exponential GARCH (EGARCH) proposed by [26] is another widely GARCH extension which considers leverage effects in the returns series. In this model, the conditional variance is presented as an asymmetric function of the lagged residuals and may be defined jointly with Equation (1) as:

$$
\ln \left(\sigma_{t}^{2}\right)=\alpha_{0}+\sum_{i=1}^{p} \alpha_{i}\left|\frac{\varepsilon_{t-1}}{\sqrt{\sigma_{t-1}^{2}}}\right|+\sum_{k=1}^{r} \gamma_{k} \frac{\varepsilon_{t-1}}{\sqrt{\sigma_{t-1}^{2}}}+\sum_{j=1}^{q} \beta_{j} \ln \left(\sigma_{t-1}^{2}\right)
$$

Alternatively, Equation (11) may be written as, for the special case of EGARCH(1, $1)$ :

$$
\ln \left(\sigma_{t}^{2}\right)=\alpha_{0}+\alpha_{1}\left(\varepsilon_{t-1}\right)+\beta_{1} \ln \left(\sigma_{t-1}^{2}\right)+\delta\left(\left|\varepsilon_{t-1}\right|-E\left(\left|\varepsilon_{t-1}\right|\right)\right)
$$

where $\delta$ (or $\gamma_{k}$ ) is the leverage parameter that would be computed along with $\alpha_{1}$ and $\beta_{1}$. Equation (12) has in its last term the difference between absolute residuals and its expectation which produces leverage effects (effects which distinguishes the impacts of positive shocks from negative shocks to the stock returns). Note that $\delta$ (or $\gamma_{k}$ ) is that parameter that accounts for the asymmetry in the model; this serves as an advantage of EGARCH over the standard GARCH model. Another significant advantage of this model is that by modelling $\ln \left(\sigma_{t}^{2}\right)$ instead of $\sigma_{t}^{2}$, the volatility estimate is certainly going to be positive. This view according to [27] is standard in the GARCH model, where there is need for model restrictions. EGARCH is however unrestricted in the course of model estimation because with the natural $\log$ of $\sigma_{t}^{2}$, the volatility equation will always be positive. The persistence to volatility is however determined by $\beta_{1}$ [28] [29].

\subsection{TGARCH}

Threshold GARCH model developed by [30] is similar to GJR-GARCH; the main difference is, rather than considering volatility as a conditional variance, the conditional standard deviation is used. The model is based on the axiom that posi- 
tive and negative shocks with the same magnitude impacts on asset price volatility differently, which according to [31], is attributed to the stylized fact called leverage effect.

TARCH model is defined mathematically along with Equation (2) as:

$$
\sigma_{t}=\alpha_{0}+\alpha_{1}^{+} \varepsilon_{t-1}^{+}+\alpha_{1}^{-} \varepsilon_{t-1}^{-}+\beta_{1} \sigma_{t-1}
$$

where

$$
\left\{\begin{array}{lll}
\varepsilon_{t-1}^{+}=\varepsilon_{t-1} & \text { if } \varepsilon_{t-1}>0 ; & \varepsilon_{t-1}^{+}=0 \text { if } a_{t-1} \leq 0 \\
\varepsilon_{t-1}^{-}=a_{t-1} & \text { if } a_{t-1} \leq 0 ; & \varepsilon_{t-1}^{+}=0 \text { if } a_{t-1} \leq 0
\end{array}\right.
$$

\section{Result and Discussion}

This section is meant to present and discuss the results of the analysis of the study; starting with the presentation of the descriptive statistics and normality tests through to the presentation of results on the models fitting and finally with the presentation of relative persistence rates between the financial crisis period and periods before and after the crisis.

\subsection{Descriptive Statistics \& Normality Tests}

Table 1 and Table 2 present the summary statistics and the normality tests for ten (10) banks being investigated for the periods of: 1) the overall period (2004-2014) and 2) financial crises (2007-2009). We observe that the mean returns for the 10 banks are not all zeros for the two periods; while the medians for overall period for the 10 banks are all zero, those of the period of financial crises are not all zeros especially for the following banks: Diamond (-0.0032), Guaranty Trust $(-0.0012)$ and UBA $(-0.001)$. Also, the standard deviations for the 10 banks are undoubtedly high compared to the mean returns across the two periods of the study, indicating high variability in the series. The remaining key findings are summarised below with respect to the periods of interest.

Table 1. Summary statistics \& normality test for return series across the 10 banks for the periods: 2004-2014.

\begin{tabular}{cccccccccccc}
\hline Bank & Sample size & Mean & Median & Max. & Min. & Std. Dev. & Skewness & Kurtosis & JB & p-value \\
\hline Access & 2417 & 0.0004 & 0.000 & 0.8540 & -0.854 & 0.0397 & 1.9603 & 218.846 & 4693516 & 0.000 \\
Diamond & 2218 & 0.0000 & 0.000 & 0.9690 & -0.951 & 0.0411 & 0.4027 & 270.742 & 6625042 & 0.000 \\
Eco & 1904 & 0.0000 & 0.000 & 6.5103 & -6.2879 & 0.2276 & 1.9553 & 673.543 & 35671655 & 0.000 \\
Guaranty & 2418 & 0.0004 & 0.000 & 2.2828 & -2.2828 & 0.0729 & -0.1445 & 799.086 & 63850608 & 0.000 \\
Skye & 2065 & 0.0000 & 0.000 & 1.8116 & -2.0592 & 0.0722 & -2.9746 & 527.504 & 23673493 & 0.000 \\
Fidelity & 2225 & 0.0003 & 0.000 & 1.1725 & -0.6968 & 0.0432 & 8.9275 & 360.332 & 8559667 & 0.000 \\
Sterling & 1883 & 0.00008 & 0.000 & 2.6546 & -2.0794 & 0.0888 & 7.6013 & 591.346 & 27176568 & 0.000 \\
UBA & 2417 & -0.0002 & 0.000 & 0.7810 & -0.7888 & 0.0417 & -0.6569 & 127.096 & 1551054 & 0.000 \\
Union & 2438 & -0.0005 & 0.000 & 1.6743 & -1.553 & 0.0709 & 5.9499 & 341.939 & 11684273 & 0.000 \\
Zenith & 2360 & 0.0000 & 0.000 & 0.3380 & -0.798 & 0.032 & -7.612 & 187.112 & 3356031 & 0.000 \\
\hline
\end{tabular}


Table 2. Summary statistics \& normality test for return series across the 10 banks for the periods: 2007-2009.

\begin{tabular}{cccccccccccc}
\hline Bank & Sample size & Mean & Median & Max. & Min. & Std. Dev. & Skewness & Kurtosis & JB & p-value \\
\hline ACCESS & 495 & -0.0016 & 0.000 & 0.0488 & -0.0513 & 0.0305 & 0.0356 & 2.1885 & 13.6870 & 0.001 \\
Diamond & 496 & -0.0019 & -0.0032 & 0.0488 & -0.1104 & 0.0330 & 0.0327 & 2.0976 & 16.9169 & 0.0002 \\
Eco & 496 & -0.005 & 0.000 & 1.5041 & -1.6094 & 0.1237 & -4.7202 & 152.0117 & 460734.3 & 0.000 \\
Guaranty & 520 & -0.0013 & -0.0012 & 0.3179 & -0.3444 & 0.0376 & -0.7486 & 27.2662 & 12806.98 & 0.000 \\
Skye & 520 & 0.0000 & 0.000 & 0.0488 & -0.0988 & 0.0324 & -0.0990 & 2.2310 & 13.6617 & 0.001 \\
Fidelity & 520 & 0.0007 & 0.000 & 0.0775 & -0.0513 & 0.0263 & 0.1437 & 2.8947 & 2.0303 & 0.3624 \\
Sterling & 519 & -0.0014 & 0.000 & 0.0917 & -0.1683 & 0.0306 & -0.2401 & 3.9312 & 23.7415 & 0.000 \\
UBA & 496 & -0.0026 & -0.001 & 0.2563 & -0.4099 & 0.0395 & -2.6256 & 34.1534 & 20627.55 & 0.000 \\
Union & 496 & -0.0018 & 0.000 & 0.0488 & -0.2026 & 0.0328 & -0.8045 & 6.9492 & 375.824 & 0.000 \\
Zenith & 522 & 0.006 & 0.000 & 4.1665 & -0.4058 & 0.1870 & 21.182 & 471.463 & 4812229 & 0.000 \\
\hline
\end{tabular}

\section{Overall Periods (2004-2014):}

In this case, the average returns are all positive except for two banks-Union and Unity banks, but are largely approximately equal to zero; and the medians are all zero for the 10 banks. The standard deviations are far higher than the average returns across the 10 banks, indicating high variability around the mean. The 10 banks are more skewed than expected of a normal distribution with fidelity bank taking the lead; four are negatively skewed while the remaining six are positively skewed. This implies that only four are exposed to negative shocks in the long run.

Also, virtually all the banks are highly leptokurtic based on relatively high kurtosis, with GTB having the highest value of 799.086; an indication of violation of Gaussian assumptions and likelihood of prolonged effects of any shock on all the banks at the overall period. Finally, Jarque-Bera tests in the $9^{\text {th }}$ columns in Table 1 show gross non-normality; and both the histogram with superimposed normal distribution curve and Q-Q plots obtained confirmed this (see the Appendix).

Augmented Dickey-Fuller (ADF) tests also indicate stationarity across the banks; the same with heteroscedasticity tests of Harvey, Breusch-Pagan and Engle (Lagrange Multiplier) LM; all confirmed the appropriateness of ARCH/GARCH family models across the banks and the two periods.

\section{Financial Crises Period (2007-2009):}

Only one of the banks' average returns is zero while the rest are non-zeros and mostly negative, except for Fidelity and Zenith banks. Also observed is that unlike the overall data, not all median returns are zero. The standard deviations are far higher than the mean returns, showing high level of variability in the data. Zenith bank returns remains the most positively skewed (with skewness of 21.78); and unlike the overall level where it was negatively skewed. The six banks, namely-Eco (-4.72), Guaranty (-0.7486), Skye (-0.099), Sterling (-0.24), UBA (-2.626) 
and Union (-0.805) are negatively skewed.

Besides the four banks-Access (2.19), Diamond (2.098), Skye (2.23) and Fidelity (2.89), having kurtosis value less than 3 as expected of a normal distribution, the remaining six have considerably high kurtosis; and the Eco with highest kurtosis of 152.01 being the most leptokurtic.

Meanwhile, the normality tests reveal that only Fidelity bank returns with p-value of 0.362 is approximately normally distributed at $5 \%$ while the remaining 9 banks are non-normally distributed (see Table 2 for the details).

\subsection{Fitting Suitable Model $^{1}$}

Having tested the suitability of the ARCH/GARCH family models, $\mathrm{ARCH}(1)$, $\operatorname{GARCH}(1,1), \operatorname{EGARCH}(1,1)$ and $\operatorname{GJR}-\operatorname{GARCH}(1,1)$ models are fitted to the returns of each bank and the Akaike Information Criterion (AIC) obtained for each period considered. The appropriate model is chosen by considering the least AIC and other relevant stationarity conditions as appropriate for each model across the four periods, results of which are provided in Table 3 and Table 4.

\section{Financial Crises Period (2007-2009):}

During these periods, the retuns of only two banks are fitted with ARCH (UBA) and GARCH (Diamond) models, whilst the remaining eight are fitted with the EGARCH model. However the volatility persistence levels are considerably high with that of UBA (1.0603) being extremely high and unstationary (see Table 3 and Figure 1). Also observed is that, the values of the leverage parameters for Union (0.113) and GTB (0.1487) show that the two banks volatility are rather dominated by positive shocks than negative shocks (see Table 3 below).

Table 3. Appropriate volatility model for each bank during financial crises (2007-2009).

\begin{tabular}{|c|c|c|c|c|c|c|}
\hline BANK & Model & $\alpha_{0}$ & $\alpha_{1}$ & $\beta_{1}$ & $\gamma_{1}$ & Persistence \\
\hline Access & $\operatorname{EGARCH}(1,1)$ & -1.2458 & 0.4779 & 0.8796 & -0.0009 & 0.8796 \\
\hline Skye & $\operatorname{EGARCH}(1,1)$ & -1.4314 & 0.5471 & 0.8596 & -0.0006 & 0.8596 \\
\hline ETI(Eco) & $\operatorname{EGARCH}(1,1)$ & -0.8781 & -0.2283 & 0.7941 & -0.2981 & 0.7941 \\
\hline Fidelity & $\operatorname{EGARCH}(1,1)$ & -2.1260 & 0.7405 & 0.7888 & -0.0504 & 0.7888 \\
\hline Sterling & $\operatorname{GARCH}(1,1)$ & 0.000098 & 0.3951 & 0.5381 & N/A & 0.9332 \\
\hline Union & $\operatorname{EGARCH}(1,1)$ & -0.9387 & 0.6121 & 0.9312 & 0.1130 & 0.9312 \\
\hline UBA & $\mathrm{ARCH}(1)$ & 0.0006 & 1.0603 & N/A & N/A & $1.0603>1$ \\
\hline Guaranty Trust & $\operatorname{EGARCH}(1,1)$ & -1.8886 & 0.7129 & 0.8060 & 0.1487 & 0.8060 \\
\hline Diamond & $\operatorname{GARCH}(1,1)$ & 0.000056 & 0.2408 & 0.7154 & N/A & 0.9562 \\
\hline Zenith & $\operatorname{EGARCH}(1,1)$ & -1.3452 & 0.7598 & 0.8827 & -0.3711 & 0.8827 \\
\hline
\end{tabular}

${ }^{1}$ Assumption of normality is proposed for the error term $\left(\varepsilon_{t}\right)$ in these models, and GARCH, EGARCH and TGARCH exhibit mean reversion to the long run (or constant) volatility $\alpha_{0}$. 
Table 4. Fitting volatility model to each bank returns at overall period (2004-2014).

\begin{tabular}{|c|c|c|c|c|c|c|}
\hline BANK & Model & $a_{0}$ & $\alpha_{1}$ & $\beta_{1}$ & $\gamma_{1}$ & Persistence \\
\hline Access & $\operatorname{ARCH}(1)$ & 0.0011 & 0.1554 & N/A & N/A & 0.1554 \\
\hline Skye & $\operatorname{TARCH}(1,1)$ & 0.000767 & 0.1740 & 0.2232 & 0.3422 & 0.5683 \\
\hline ETI(Eco) & $\operatorname{EGARCH}(1,1)$ & -3.6952 & 0.1610 & 0.3107 & 0.0445 & 0.3107 \\
\hline Fidelity & $\operatorname{EGARCH}(1,1)$ & -1.9844 & 0.4555 & 0.7570 & -0.1049 & 0.7570 \\
\hline Sterling & $\mathrm{ARCH}(1)$ & 0.0007 & 0.6960 & N/A & N/A & 0.6960 \\
\hline Union & $\operatorname{ARCH}(1)^{*}$ & 0.0034 & 0.2381 & N/A & N/A & 0.2381 \\
\hline UBA & $\operatorname{TGARCH}(1,1)$ & 0.0006 & 0.1485 & 0.3722 & 0.2565 & 0.6490 \\
\hline Guaranty Trust & $\mathrm{ARCH}(1)$ & 0.0031 & 0.0818 & N/A & N/A & 0.0818 \\
\hline Diamond & $\mathrm{ARCH}(1)$ & 0.001132 & 0.1494 & N/A & N/A & 0.1494 \\
\hline Zenith & $\operatorname{ARCH}(1)^{*}$ & 0.00029 & 0.7855 & N/A & N/A & 0.7855 \\
\hline
\end{tabular}

\section{Fin. Crisis}

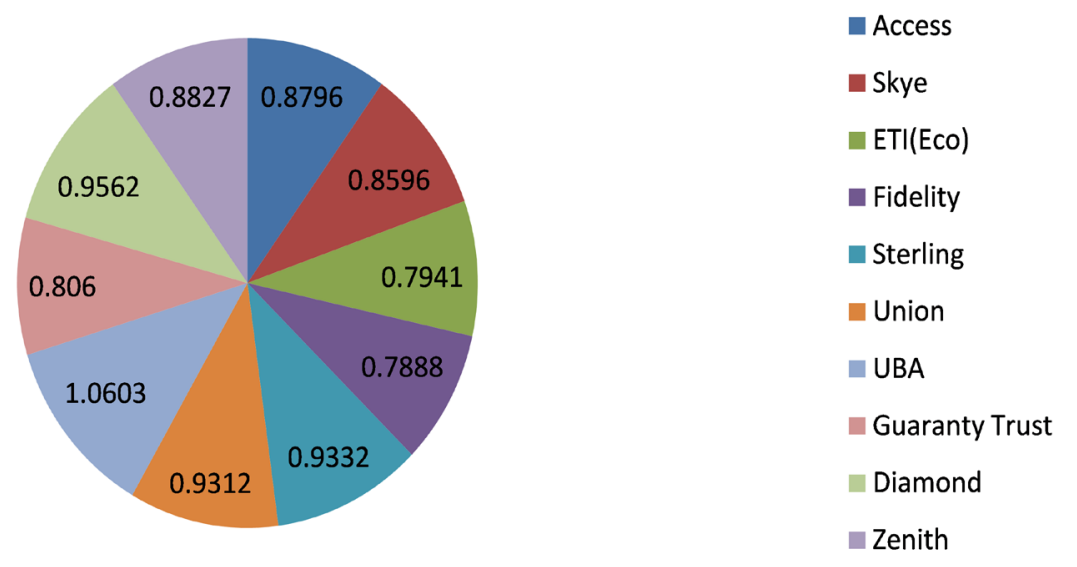

Figure 1. Pie chart showing volatility persistence in financial crisis period.

\section{Overall Periods (2004-2014):}

For the overall periods covered, it is noticed that only four banks, Eco, Fidelity, Skye and UBA are characterised by Asymmetric GARCH models, whereas the remaining six are characterised by $\mathrm{ARCH}(1)$ model. Zenith bank appears to be most volatility persistent with a value of 0.7855 , followed by Fidelity with persistent value 0.7570 . However generally the volatility persistent level has been overtaken by events for being considerably low (see Table 4).

\section{Obtaining Relative Persistence in Volatility}

In this case, we try to compute relative volatility persistence $(R P)$ of the financial crisis period relative to the overall. This is intended to determine what proportion of the overall persistence in volatility was accounted for during the crisis. This would enable us to undersatand level of risk that was recorded by each bank during the period. 
Suppose that the persistence in volatility during the crisis and at the overall period is respectively defined as $P_{F C}$ and $P_{T}$, the relative persistence in volutility during the crisis is then defined mathematically as:

$$
R P_{F C / T}=\frac{\text { PERSISTENCE during FINCIAL CRISIS }}{\text { PERSISTENCE at the OVERALL }}
$$

For Example:

$$
R P_{F C}(\text { Access bank })=\frac{P_{c}}{P_{T}}=\frac{0.8796}{0.1855}=5.66
$$

(see columns 5 and 6 of Table 4).

With this result, Access bank's persistence during the financial crisis was about 6 times that of the overall period and GTB having the highest relative persistence (see col. 4 of Table 5 below). It could be deduced that persistence during crisis is far above that of the overall period, with the relative persistence of GTB taking the lead, about 10 times higher during the crisis (see Table 4 and Figure 2).

Figure 2 below displays the persistence in volatility across the ten banks, before, during and after the 2008-2009 financial crises. Apparently, Zenith bank was mostly volatile before the crisis; whereas UBA and Fidelity banks were mostly volatile during and after the crisis respectively (see Figure 2).

Table 5. Relative volatility persistence due to financial crisis.

\begin{tabular}{cccc}
\hline BANK & $\boldsymbol{P}_{T}$ & $\boldsymbol{P}_{F C}$ & $\boldsymbol{R} \boldsymbol{P}_{F C / T}$ \\
\hline Access & 0.1554 & 0.8796 & 5.660232 \\
Skye & 0.5683 & 0.8596 & 1.512581 \\
ETI(Eco) & 0.3107 & 0.7941 & 2.555842 \\
Fidelity & 0.7570 & 0.7888 & 1.042008 \\
Sterling & 0.6960 & 0.9332 & 1.340805 \\
Union & 0.2381 & 0.9312 & 3.910962 \\
UBA & 0.6490 & 1.0603 & 1.633744 \\
Guaranty Trust & 0.0818 & 0.8060 & 9.853301 \\
Diamond & 0.1494 & 0.9562 & 6.400268 \\
Zenith & 0.7855 & 0.8827 & 1.123743 \\
\hline
\end{tabular}



Figure 2. Volatility persistence pre, during and post financial crisis. 


\section{Summary and Conclusions}

\subsection{Summary}

In this study, ten banks that make up the NSE banking Index of the Nigerian Stock Exchange are considered. The daily closing prices of stocks of these banks starting from June 2004 to May, 2014, covering periods of banks consolidation, post consolidation, global financial crises and post financial crisis encompassing the periods of second and major reforms initiated by the Central bank of Nigeria were obtained, from which returns are generated. Having obtained the summary statistics of each of these returns, tests of normality are observed to determine if each of these returns could be described via a Gaussian distribution. While establishing the normality condition of the returns, both price and returns series plots as well as Quantile-Quantile plots for each of the banks at the overall level were obtained as a further proof justifying the results of our tests (See Appendix: Figures A1-A20).

The results of the tests show that all the banks are highly leptokurtic the given the very high value of kurtosis far above 3 that is expected of a Gaussian distribution. This is further confirmed by the p-values obtained from Jarque-Bera (JB) tests (see Table 1). Meanwhile for the two periods of interest, it is found that GTB and Zenith are the most leptokurtic with the highest kurtosis of 799.086 and 471.463 , recorded by the banks at the overall and during the financial crisis respectively. The Adjusted Dickey Fuller test was employed in checking for the stationarity of the series across the two periods and the corresponding p-values confirmed the stationary for each of the banks.

The Heteroscedasticity tests and residual plots for the two periods were significant for the ten (10) banks, indicating suitability for fitting the ARCH/GARCH family models to the returns of these banks across the 2 periods and this was further confirmed by the results obtained. Having fitted the models, relevant models assumptions/constraints and the least AIC rule were adopted in choosing appropriate model to fit respective banks volatility. Estimates of the fitted model parameters and the volatility persistence were obtained; and the results displayed in Table 3 and Table 4 above. The empirical results show that both EGARCH and TGARCH became the most favoured candidate models, particularly during the financial crisis periods. Also from the results, it is noted that volatility persistence was very high between 2007 and 2009 with UBA having a value higher than one, indicating non-stationarity and possible explosiveness in volatility.

The results of relative persistence obtained also show that the financial crisis has led to significant increase in volatility persistence, with GTB having the highest relative persistence (see Table 4, Figure 1 and Figure 2).

\subsection{Conclusions}

The outcomes of this study show that different ARCH/GARCH models were fitted to the volatility of each of the 10 banks at the two study periods. The events of global financial market had significant impacts on the stock returns of these 
banks; thereby giving way for asymmetric GARCH models to be the most appropriate models to describe the returns behaviour during the crisis. It was also deduced that the returns behaviour cannot be described by a normal distribution due to the leptokurtic behaviour of stock returns of each of the banks across the two periods covered by this research.

Also worthy of note is that assumption of residuals of the ARCH family models following a normal distribution was made while fitting the respective model. However this assumption has generally being supported with mixed views among researchers who believe that returns residuals are better assumed to follow tailed distribution such as t-distribution and Generalized error distribution

Due to the higher rates of persistence in volatility during the financial crisis across the 10 banks than they were at the overall period, is an indication that the banks became riskier due to the crisis.

\section{Conflicts of Interest}

The authors declare no conflicts of interest regarding the publication of this paper.

\section{References}

[1] Seda, P. (2012) Impact of the Global Financial Crisis on Stock Market Volatility: Evidence from Central European Stock Market. In: Proceedings of 30 th International Conference Mathematical Methods in Economics, 787-792.

[2] Patel, S.A. and Sarkar, A. (1998) Crises in Developed and Emerging Stock Markets. Financial Analysts Journal, 54, 50-61. https://doi.org/10.2469/faj.v54.n6.2225

[3] Sakthivel, P., Raghuram, G., Veerakumar, K. and Sumathisri, B. (2014) Time to Maturity and Volume Effects on Volatility: Evidence from NSE Futures Market. Asian Social Science, 10, 75. https://doi.org/10.5539/ass.v10n18p75

[4] Verma, S. and Mahajan, N. (2012) Stock Return, Volatility and the Global Financial Meltdown: The Behavior of Indian Stock Market. International Journal of Arts and commerce, 1, 166-178.

[5] Ali, R. and Afzal, M. (2012) Impact of Global Financial Crisis on Stock Markets: Evidence from Pakistan and India. E3 Journal of Business Management and Economics, 3, 275-282.

[6] Adamu, A. (2010) Global Financial Crisis and Nigerian Stock Market Volatility. Conference on Managing The Challenges of Global Financial Crisis in Developing Economies, Nasarawa State University, Keffi, Nigeria.

[7] Sanusi, L.S. (2012) Banking Reforms and Its Impact on Nigerian Economy. Being a Lecture Delivered at the University of Warwick's Economic Summit, UK 17th February. Research Department Abuja CBN.

[8] Engle, R.F. (1982) Autoregressive Conditional Heteroscedasticity with Estimates of the Variance of United Kingdom Inflation. Econometrica: Journal of the Econometric Society, 50, 987-1007. https://doi.org/10.2307/1912773

[9] Bollerslev, T. (1986) Generalized Autoregressive Conditional Heteroskedasticity. Journal of Econometrics, 31, 307-327.

https://doi.org/10.1016/0304-4076(86)90063-1 
[10] Bollerslev, T. and Mikkelsen, H.O. (1996) Modeling and Pricing Long Memory in Stock Market Volatility. Journal of Econometrics, 73, 151-184. https://doi.org/10.1016/0304-4076(95)01736-4

[11] Engle, R. (2001) GARCH 101: The Use of ARCH/GARCH Models in Applied Econometrics. Journal of Economic Perspectives, 15, 157-168. https://doi.org/10.1257/jep.15.4.157

[12] Brooks, R. (2002) Asset-Market Effects of the Baby Boom and Social-Security Reform. American Economic Review, 92, 402-406. https://doi.org/10.1257/000282802320191697

[13] Karunanayake, I., Valadkhani, A. and O'brien, M. (2010) The Effects of Financial Crises on International Stock Market Volatility Transmission. School of Economics, University of Wollongong, Australia. https://doi.org/10.1111/j.1467-8454.2010.00397.x

[14] Lamoureux, C.G. and Lastrapes, W.D. (1990) Heteroskedasticity in Stock Return Data: Volume versus GARCH Effects. The Journal of Finance, 45, 221-229. https://doi.org/10.1111/j.1540-6261.1990.tb05088.x

[15] Lamoureux, C.G. and Lastrapes, W.D. (1990) Persistence in Variance, Structural Change, and the GARCH Model. Journal of Business \& Economic Statistics, 8, 225-234. https://doi.org/10.1080/07350015.1990.10509794

[16] Stock, J.H. and Watson, M.W. (1998) Median Unbiased Estimation of Coefficient Variance in a Time-Varying Parameter Model. Journal of the American Statistical Association, 93, 349-358. https://doi.org/10.1080/01621459.1998.10474116

[17] Franses, P.H. and Van Dijk, D. (1996) Forecasting Stock Market Volatility Using (Nonlinear) GARCH Models. Journal of Forecasting, 15, 229-235. https://doi.org/10.1002/(SICI)1099-131X(199604)15:3<229::AID-FOR620>3.0.CO;2-3

[18] Amir, A., Wasiuzzaman, S., Bulsara, H.P., Gandhi, S., Porey, P.D. and Chen, H.-L. (2010) Modeling the Effects of the Global Financial Crisis on the Malaysian Market. International Journal of Trade, Economics and Finance, 1, 387. https://doi.org/10.7763/IJTEF.2010.V1.68

[19] Chong, C.Y. (2011) Effect of Subprime Crisis on US Stock Market Return and Volatility. Global Economy and Finance Journal, 4, 102-111.

[20] Bera, A.K. and Higgins, M.L. (1993) ARCH Models: Properties, Estimation and Testing. Journal of Economic Surveys, 7, 305-366. https://doi.org/10.1111/j.1467-6419.1993.tb00170.x

[21] Tsay, R.S. (2014) An Introduction to Analysis of Financial Data with R. John Wiley \& Sons, New York, 185.

[22] Gautier, A. (2006) Asymptotic Inefficiency of Mean-Correction on Parameter Estimation for a Periodic First-Order Autoregressive Model. Communications in Statistics- Theory and Methods, 35, 2083-2106. https://doi.org/10.1080/03610920600761873

[23] Glosten, L.R., Jagannathan, R. and Runkle, D.E. (1993) On the Relation between the Expected Value and the Volatility of the Nominal Excess Return on Stocks. The Journal of Finance, 48, 1779-1801. https://doi.org/10.1111/j.1540-6261.1993.tb05128.x

[24] Taylor, S.J. (2011) Asset Price Dynamics, Volatility, and Prediction. Princeton University Press, Princeton, NJ. https://doi.org/10.1515/9781400839254

[25] Brooks, C. (2008) RATS Handbook to Accompany Introductory Econometrics for Finance. https://doi.org/10.1017/CBO9780511814082 
[26] Nelson, D.B. (1991) Conditional Heteroskedasticity in Asset Returns: A New Approach. Econometrica: Journal of the Econometric Society, 59, 347-370. https://doi.org/10.2307/2938260

[27] Thomas, S. and Mitchell, H. (2005) GARCH Modeling of High-Frequency Volatility in Australia's National Electricity Market. System, 1-39.

[28] McMillan, N.J., Holland, D.M., Morara, M. and Feng, J.Y. (2010) Combining Numerical Model Output and Particulate Data Using Bayesian Space-Time Modeling. Environmetrics, 21, 48-65. https://doi.org/10.1002/env.984

[29] Mcmillan, D.G. and Ruiz, I. (2009) Volatility Persistence, Long Memory and Time-Varying Unconditional Mean: Evidence from 10 equity indices. The Quarterly Review of Economics and Finance, 49, 578-595.

https://doi.org/10.1016/j.qref.2007.09.006

[30] Zakoian, J.M. (1994) Threshold Heteroskedastic Models. Journal of Economic Dynamics and Control, 18, 931-955. https://doi.org/10.1016/0165-1889(94)90039-6

[31] Black, F. (1976) The Pricing of Commodity Contracts. Journal of Financial Economics, 3, 167-179. https://doi.org/10.1016/0304-405X(76)90024-6 
Appendix

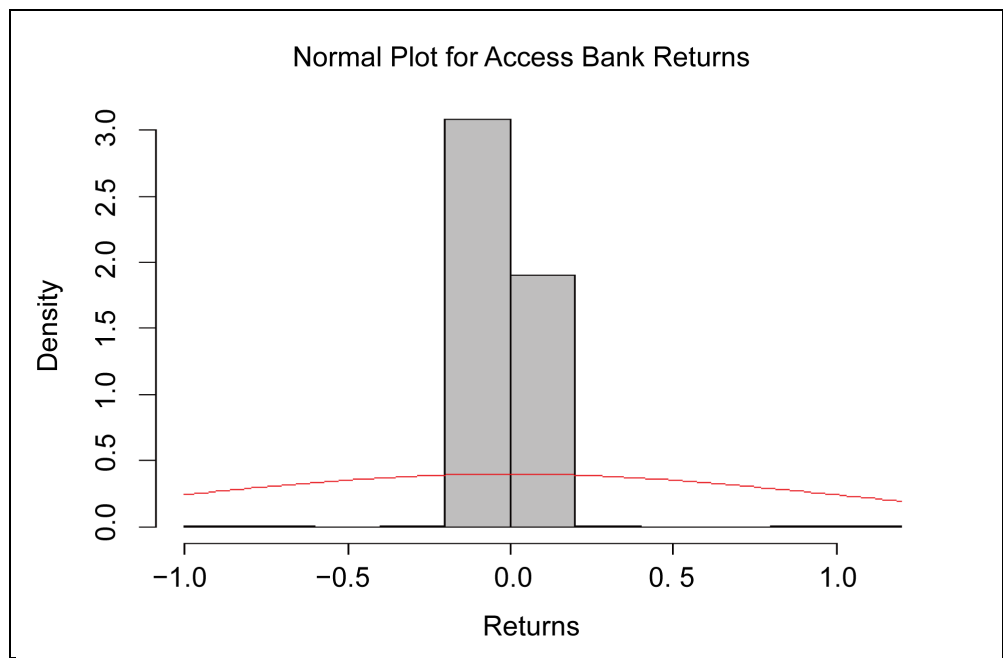

Figure A1. Normal Plot of Access Bank for 2004-2014.

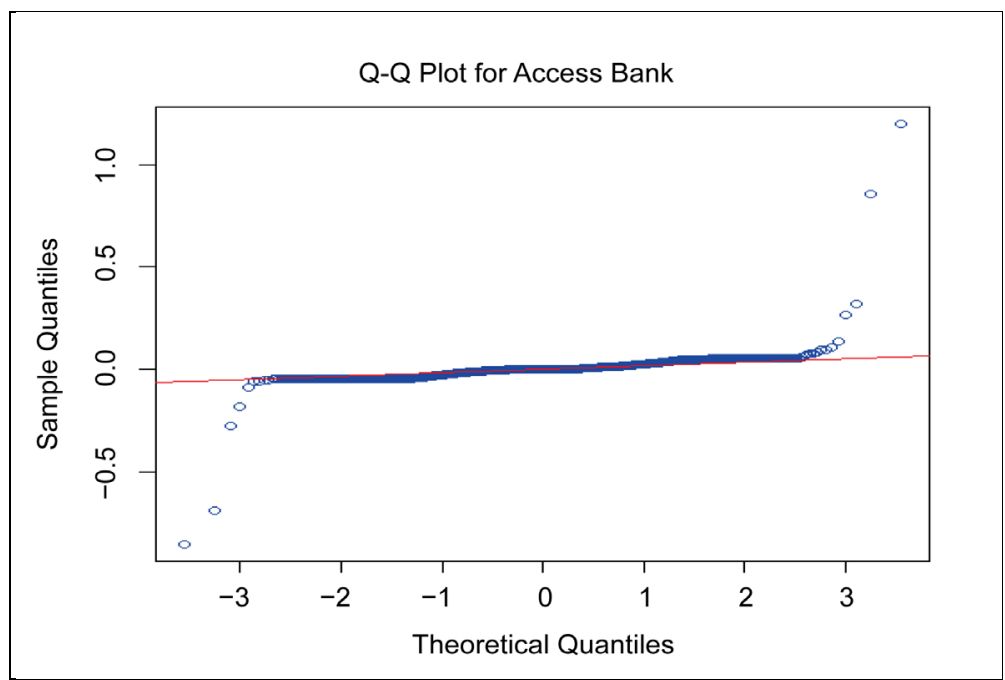

Figure A2. Q-Q Plot of Access Bank for 2004-2014.

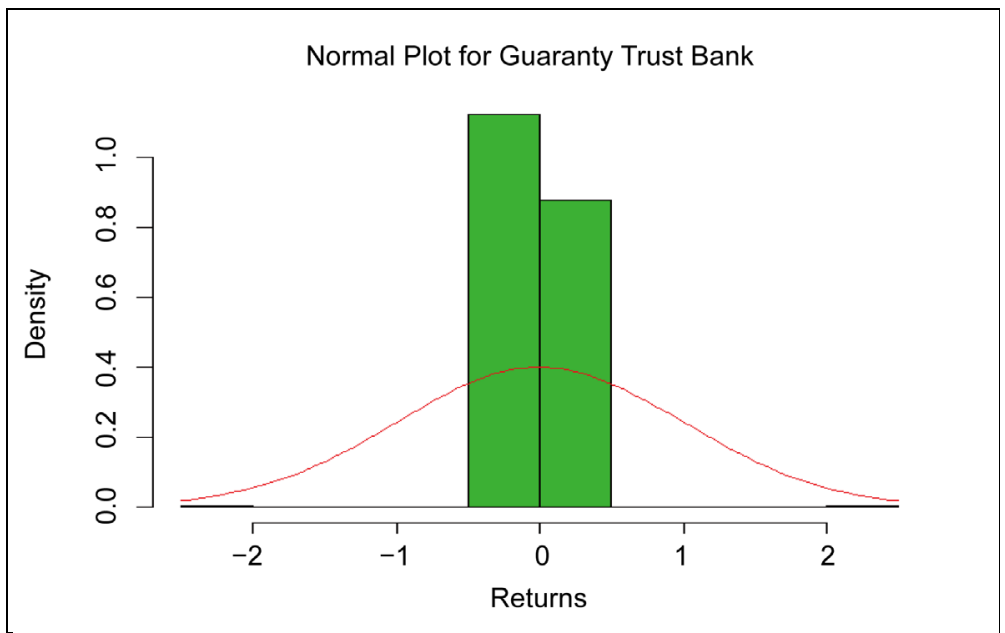

Figure A3. Normal Plot of GTB for 2004-2014. 


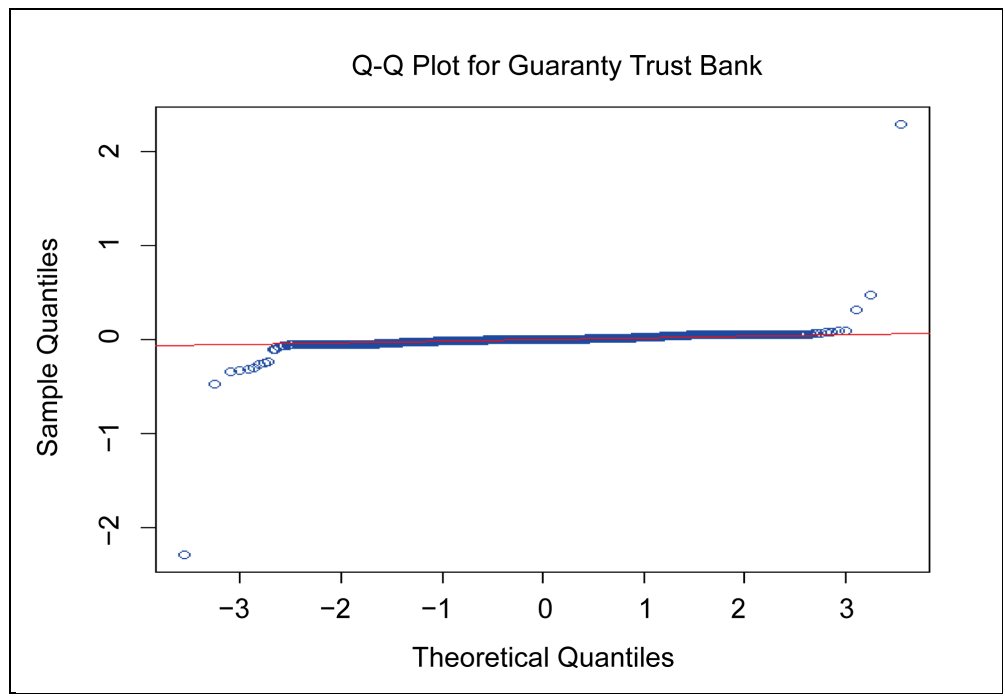

Figure A4. Q-Q Plot of GTB for 2004-2014.

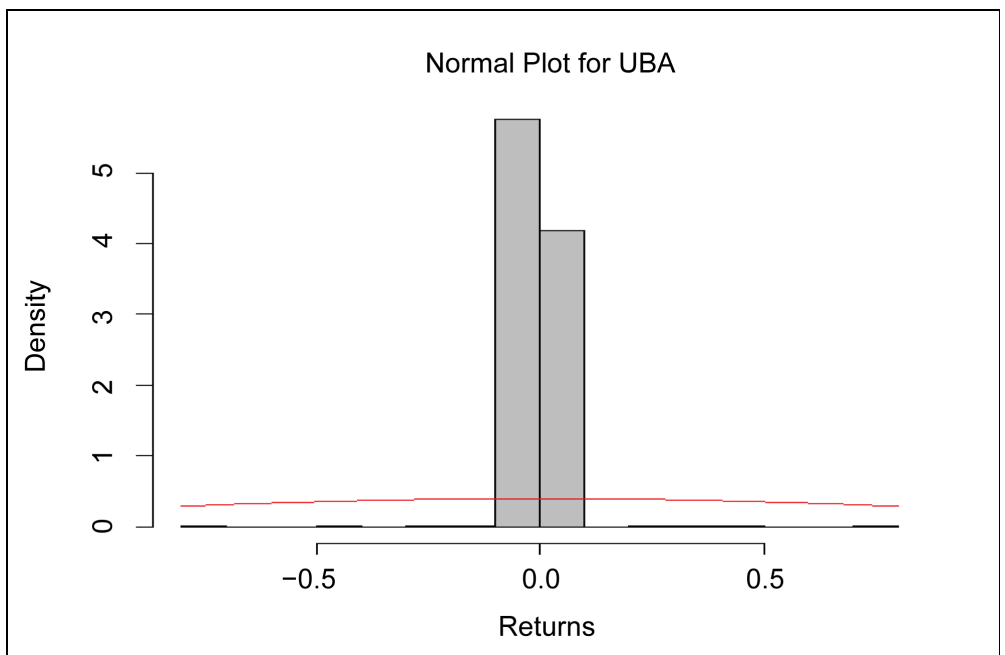

Figure A5. Normal Plot of United Bank for Africa (UBA) for 2004-2014.

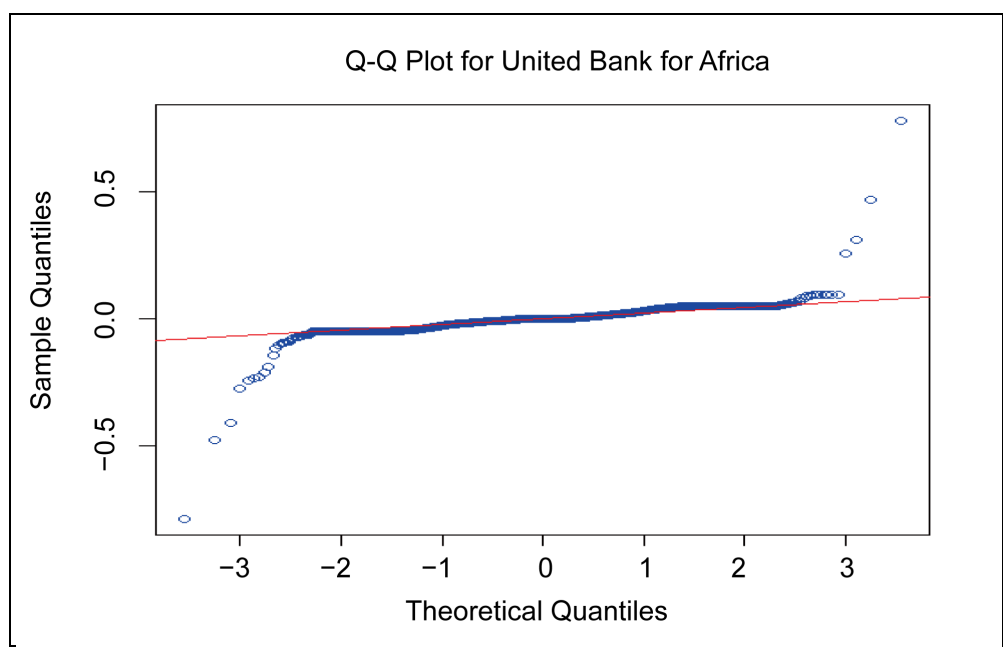

Figure A6. Q-Q Plot of UBA for 2004-2014. 


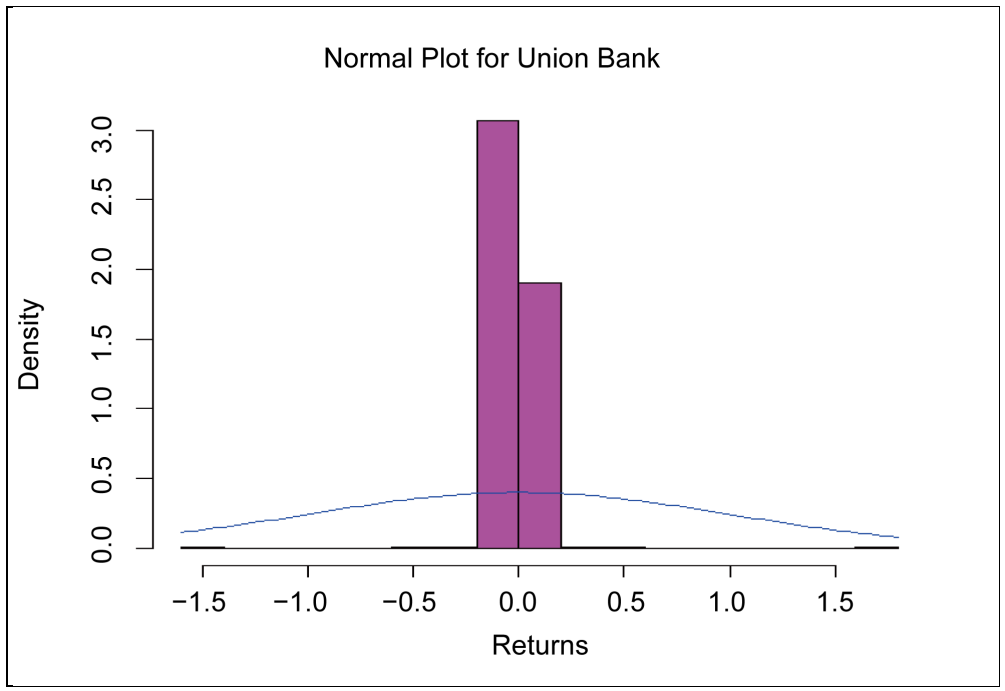

Figure A7. Normal Plot of Union Bank for 2004-2014.

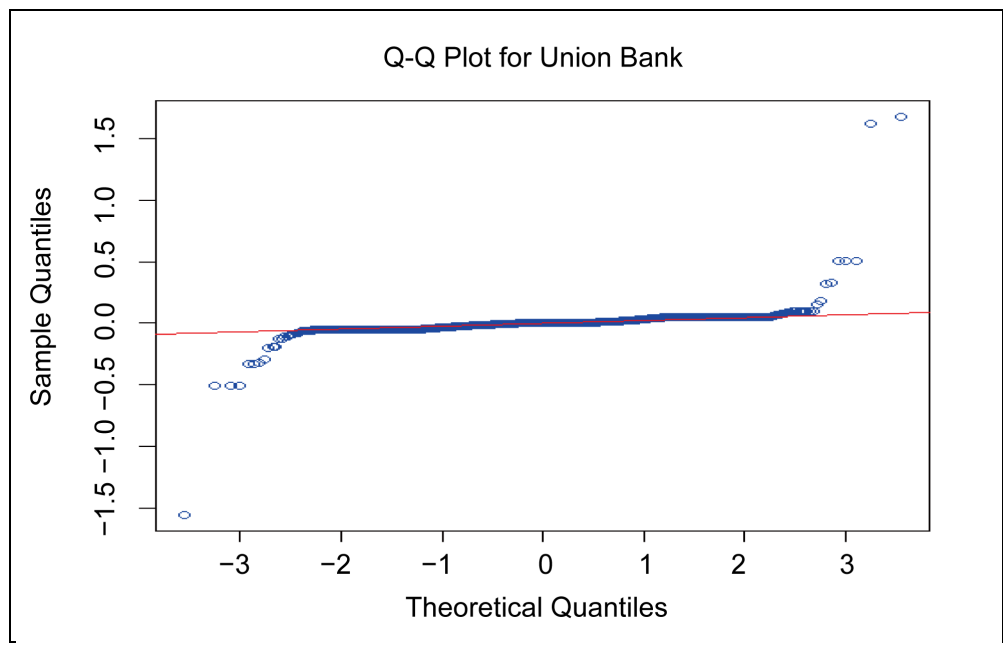

Figure A8. Q-Q Plot of Union Bank for 2004-2014.

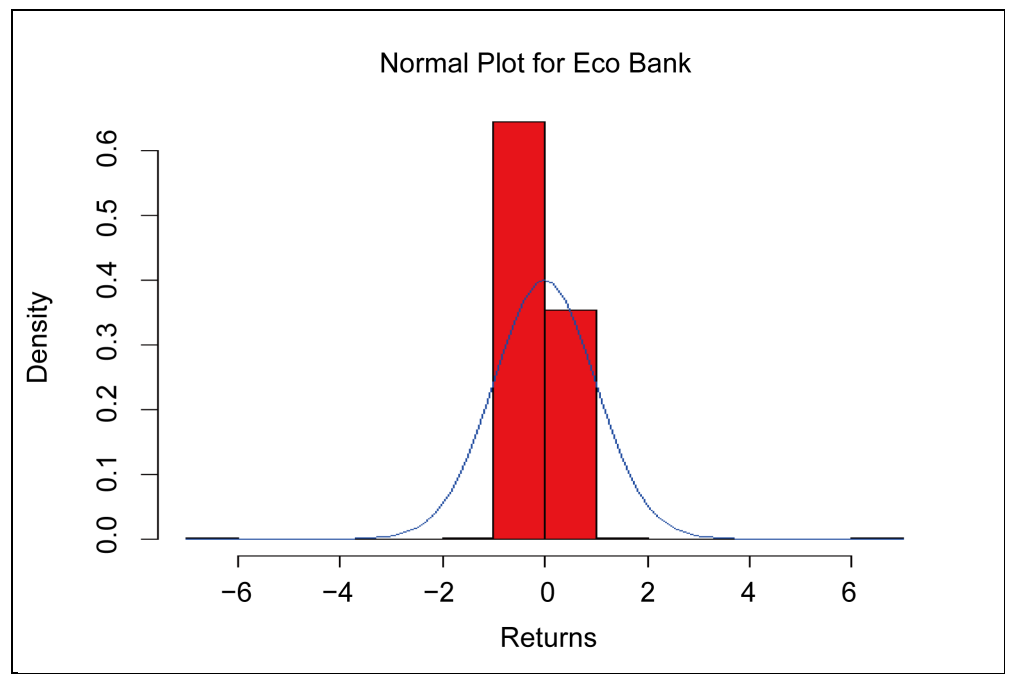

Figure A9. Normal Plot of Eco Bank for 2004-2014. 


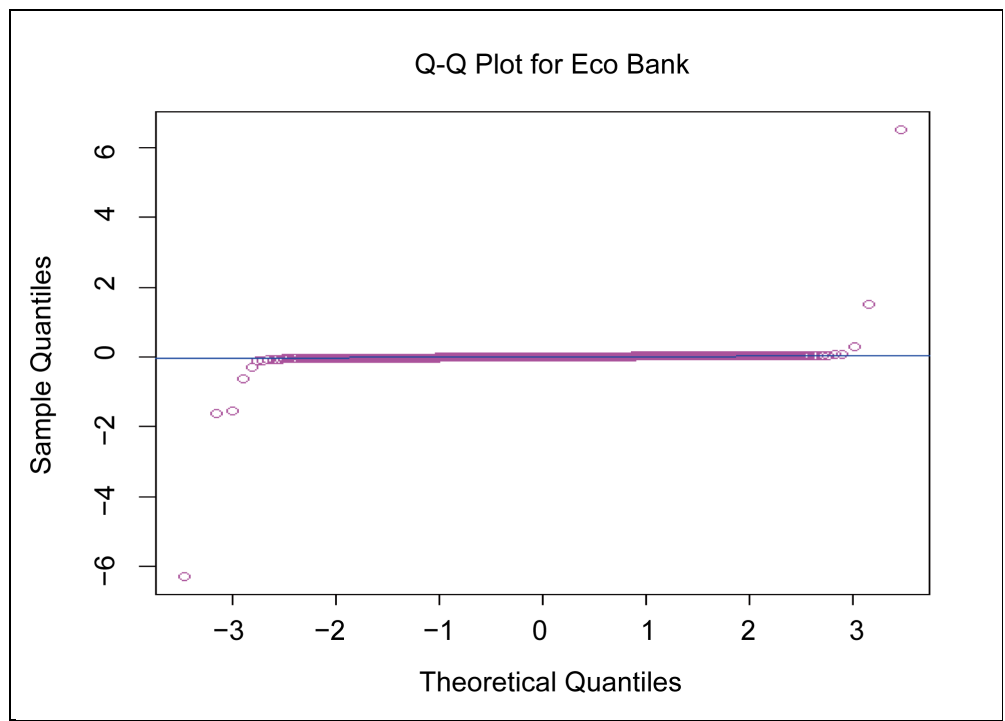

Figure A10. Q-Q Plot of Eco Bank for 2004-2014.

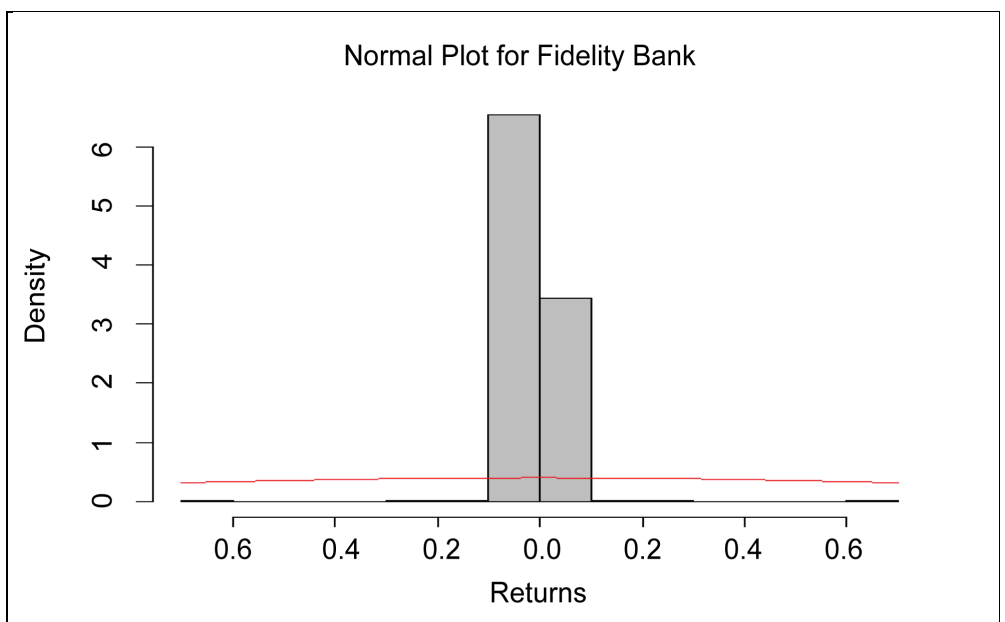

Figure A11. Normal Plot of Fidelity Bank for 2005-2014.



F igure A12. Q-Q Plot of Fidelity Bank for 2005-2014. 
Normal Plot for Skye Bank

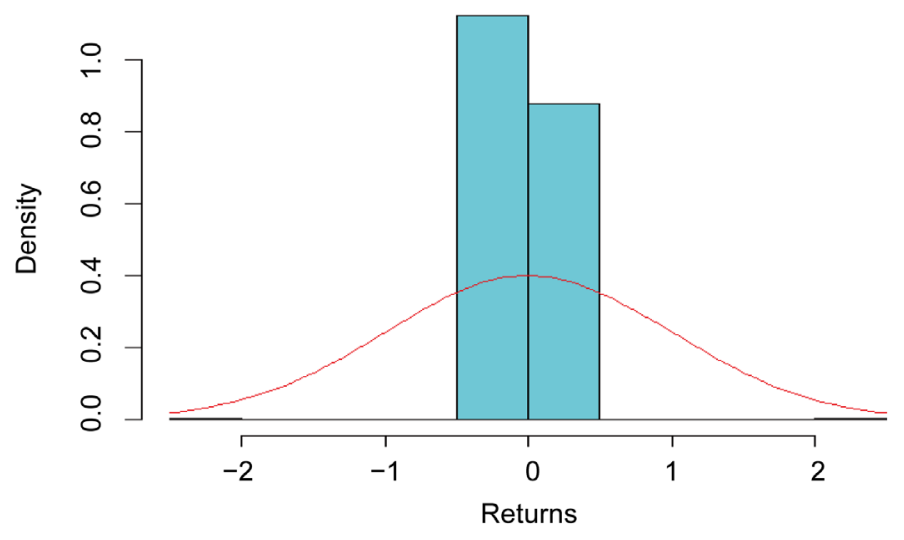

Figure A13. Normal Plot of Skye Bank for 2006-2014.

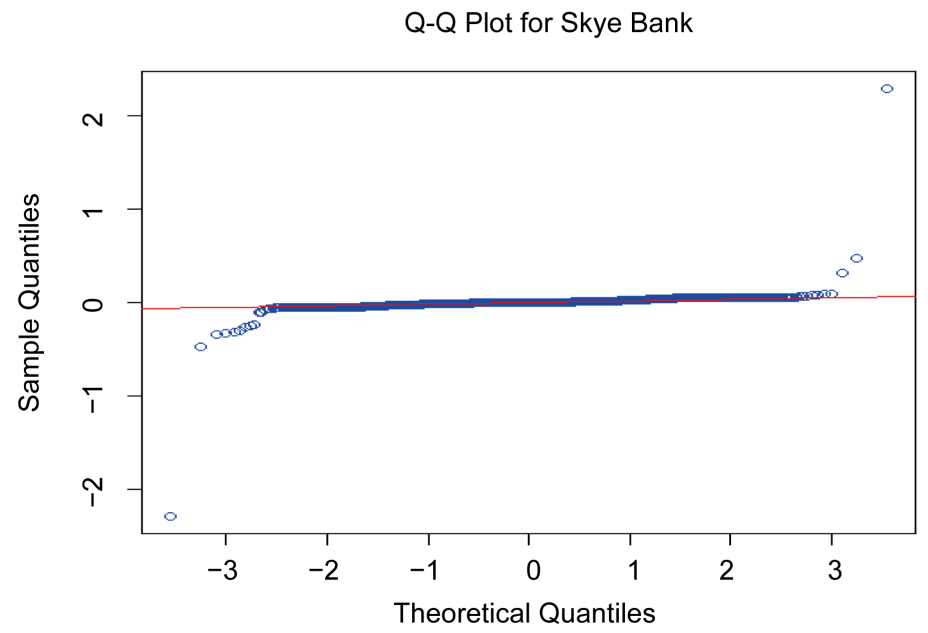

Figure A14. Q-Q Plot of Skye Bank for 2006-2014.

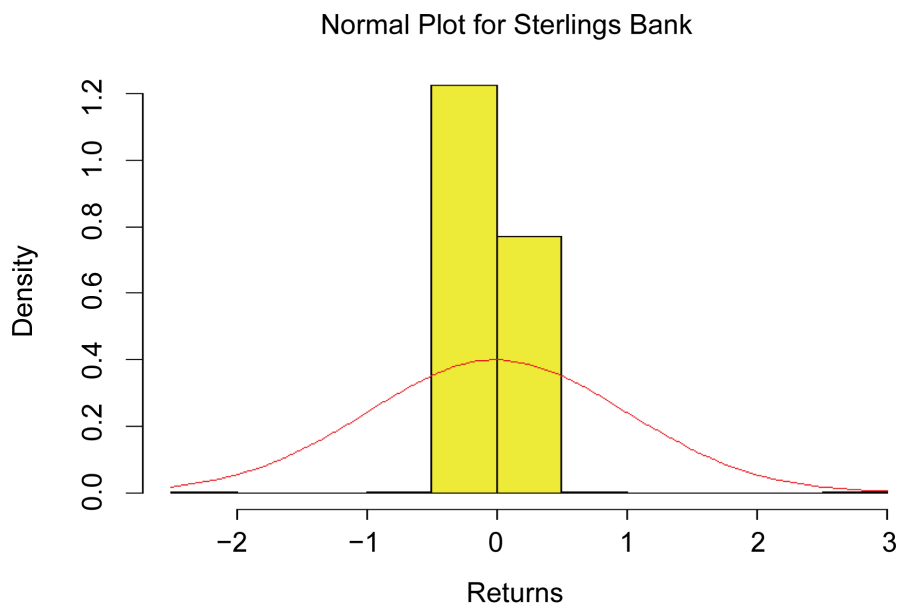

Figure A15. Normal Plot of Sterling's Bank for 2006-2014. 


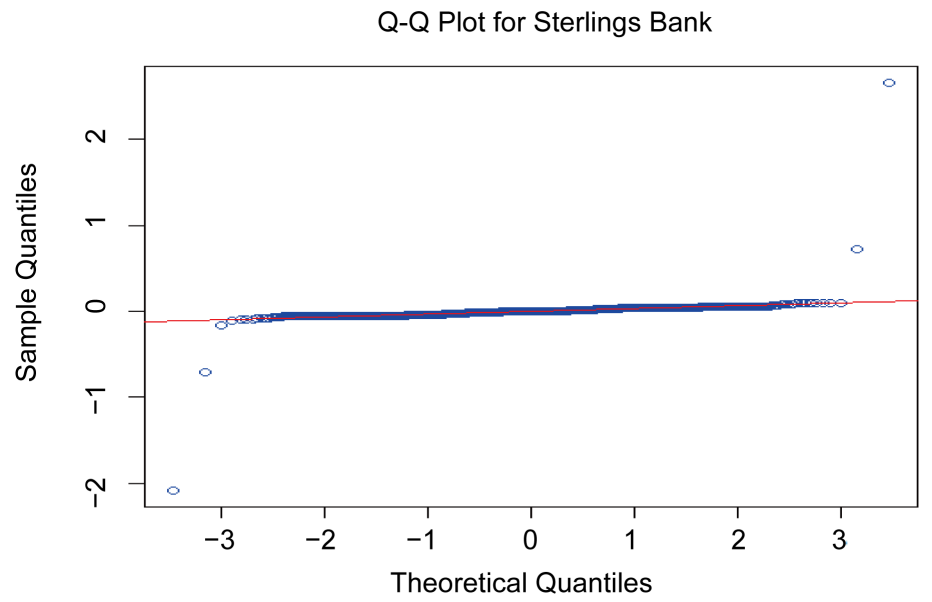

Figure A16. Q-Q Plot of Sterling's Bank for 2006-2014.

Normal Plot for Diamond Bank Returns

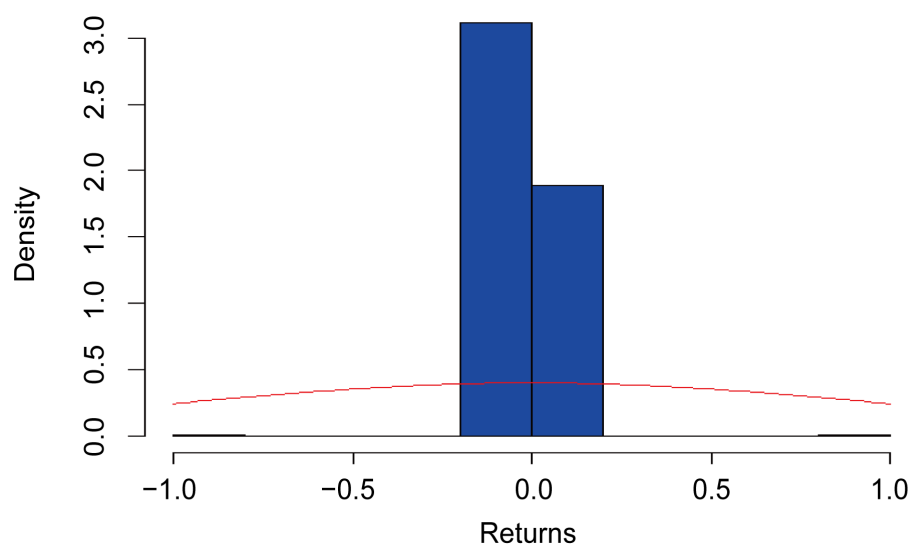

Figure A17. Normal Plot of Diamond Bank for 2005-2014.

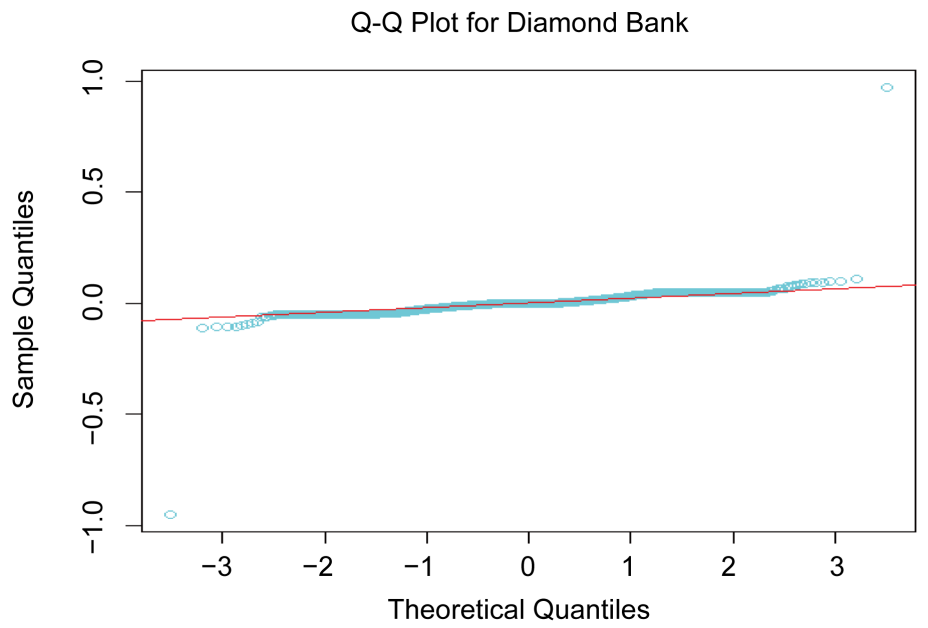

Figure A18. Q-Q Plot of Diamond Bank for 2005-2014. 
Normal Plot for Zenith Bank

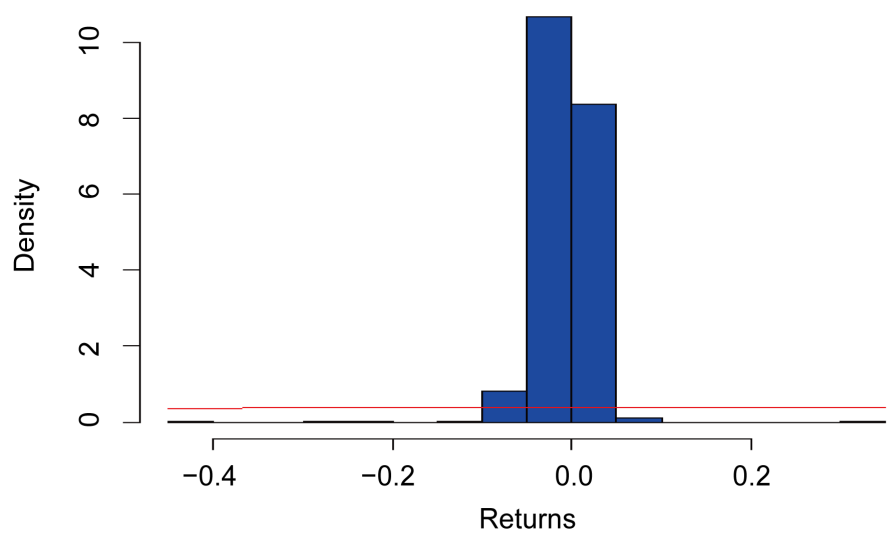

Figure A19. Normal Plot of Zenith Bank for 2004-2014.

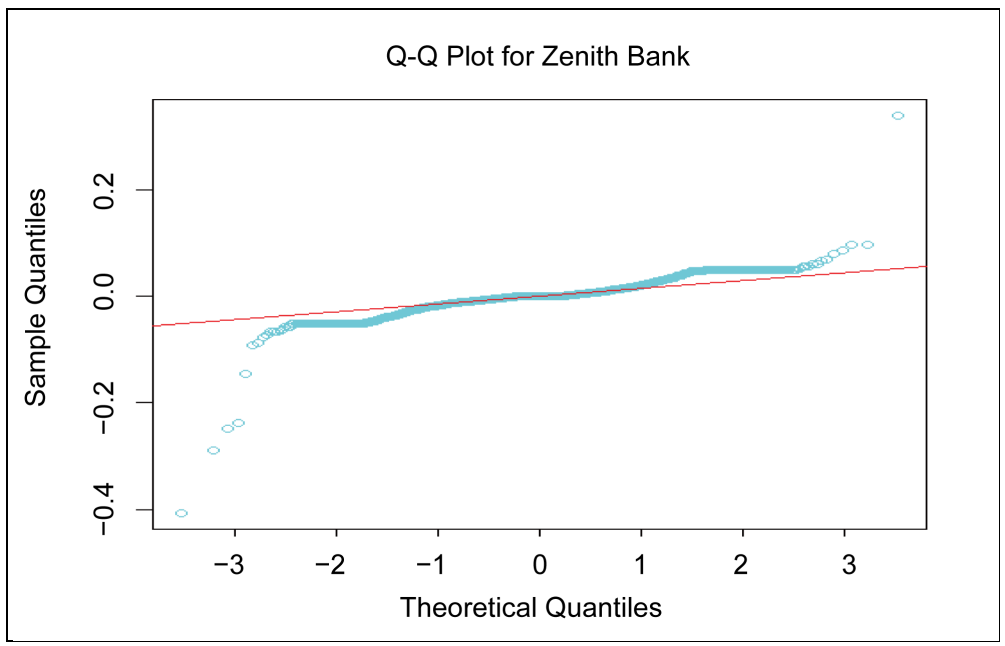

Figure A20. Q-Q Plot of Zenith Bank for 2004-2014.

The formula for the (log) returns standard deviation, skewness and kurtosis are respectively:

$$
\begin{gathered}
S_{r}=\sqrt{\frac{\sum_{t=1}^{T}\left(r_{t}-\mu\right)^{2}}{T}} \\
\hat{s}_{k r}=\frac{1}{T} \sum_{t=1}^{T}\left[\frac{r_{t}-\mu}{s_{r}}\right]^{3} \\
\hat{k}_{r}=\frac{1}{T} \sum_{t=1}^{T}\left[\frac{r_{t}-\mu}{s_{r}}\right]^{4}
\end{gathered}
$$

where, $\mu$ is the mean $(\log )$ returns. 